\title{
An Analysis of the Current Situation of College Students' Learning: Based on Survey Research Concerning the Need of Wuyi University to Increase College Students' Obligations
}

\author{
Chi Zhou ${ }^{1 *}$, George Zhuang ${ }^{2}$ and Wenbo $\mathrm{Li}^{1}$ \\ ${ }^{1}$ School of Civil Engineering and Architecture, Wuyi University, China \\ ${ }^{2}$ Department of History, University of Florida, USA
}

*Corresponding author: Chi Zhou, School of Civil Engineering and Architecture, Wuyi University, China, Email ID: 1903617355@qq.com

Received Date: March 17, 2020

Published Date: March 26, 2020

\section{Abstract}

Since the start of the $21^{\text {st }}$ century, the generations of the 1980s and 1990s were already a significant force influencing the development of the younger generations. This is especially true of the post-90s age, which has dispersed throughout the country to major colleges and universities. It is clear now that they have become the backbone of social development and shoulder the historical responsibility of China's dream of great rejuvenation. This paper explores the current situation of contemporary college students' learning, whether to increase student obligations and in-depth thinking about the factors that affect modern college students' learning, to raise awareness of the problem, and to provide more effective suggestions for the solving of such issues.

Keywords: College students; Increasing obligation; Learning status; Problem analysis

\section{Introduction}

With the passage of time, the influence of college students on society is more and more extensive and profound. Since the $21^{\text {st }}$ century, the competition among regions and countries in the world has become increasingly fierce. As a result, competition for talent has become one of the main ways to gain an advantage over competitors. Therefore, college students, who are the recipients of modern education, have rightfully received more and more attention from people from all walks of life. These very same college students shoulder the responsibility and mission of social development and progress. They are the future and the hope of China. Because of the increasingly rapid development of society today, it is necessary to fully understand the current situation of contemporary college students' learning, to identify problems in a timely manner, and to analyze and alleviate these problems. By doing so, we can improve the overall quality of college students by raising the standards of university education, and through the improvement of college students, improve society as a whole. In this way, the China that we have all dreamed of will be able to come to fruition as soon as possible.

Changes in the Educational Circumstances of Contemporary College Students

\section{Changes in the social environment}

Contemporary college students are currently the chief beneficiaries of the new era and of modern society. They grew up in an age of great societal reform and the "opening-up" of China to foreign cultures and society. They have witnessed the substantial changes that have occurred as a result. They also enjoy the advantages brought by such reform and opening-up. However, with the continuous development of society and the continuous improvement of the Chinese economy came a trend that can be described as "money worship." This new trend, unbeknownst in pre-reform times, is becoming more and more popular in this new era of materialism and is consistently impacting the thoughts and values of contemporary college students. For contemporary college 
students, whether they can handle all aspects of society and make effective use of their learning, to realize the advantageous position their learning puts them; this will be an altogether different kind of test.

\section{Changes in college students themselves}

In the past, the generation of college students of the post-80s, who had no high-tech surroundings, little material enjoyments, and simple yet substantial childhoods, entered an era of scientific and technological progress and informational development. In this special period of the country's vigorous development, they were instilled with the lofty ideals of becoming "successors of communism," from their respective childhoods. Now compare this to the generations of the post-90s, many of whom have set their own goals. The generation of college students of the post-90s, born during the national implementation of the family planning policy, many of them grew up an only child, spoiled by parents and grandparents alike. Compared with the generation of the post80s, they lack an ethic of hard work and a personal experience of self-struggle, resulting in an ability to combat opposition and frustration that is generally inferior to the generation of the post80s. This results in the older generations labeling the post-90s generation as "capricious," "selfish" and even "rebellious" when they talk about them, thinking that they lack firm willpower, have no ideals or morals, and will consequently be unable to shoulder the social responsibilities of national development and progress that their forebears were tasked with.

\section{Changes in information technology}

With the rapid global rise of the Internet in the 1980s and 1990s, information technology has increasingly become an overwhelming force in our lives. How then do college students, the highly educated younger generations, stay away from the technology and services that the "Internet" has to offer? The Internet, after all, is characterized as a system consisting of vast amounts of accessible information, fast disseminating, and having an imperfect management system. As a result, it does not only provide college students with more help in learning but also spreads negative, corrupt, and backward ideas and cultures. Nowadays, the addiction of college students to the Internet is no longer a small-scale problem, but a common phenomenon in colleges and universities throughout the country. A series of events, such as playing mobile phone games in class, truancy, and playing online video games all night, have been commonplace due to widespread addiction to the Internet and its services.

\section{Changes in the employment situation}

The population of college students in the country has increased considerably, and the problem of employment caused by it is selfevident. There is a serious imbalance between the number of employable college students and the positions available for them to take. The more college-educated individuals there are, the greater the competition for employment there will be. This will put a great many life pressures on newly graduated college students, about to enter the workforce. Many colleges and universities recognize this problem. Consequently, they encourage college students to learn and cultivate relevant skills, so that they can be better prepared for their entrance into the workforce and into society. However, if we only pay attention to the employment rate with the sole objective of achieving a specific statistical goal, we will undoubtedly move students to feelings of recalcitrance and ultimately lead to students' loss of interest in learning.

\section{The Current State of College Students Learning}

\section{Learning is disoriented and lacks motivation}

Today's college students lack motivation and a genuine desire for knowledge and are becoming more and more infatuated with their smartphones. With the rapid spread of the Internet, the generation of the post-90s has become almost zombified, constantly checking their smartphones with heads bowed low. This has become a common trend throughout college and university campuses. Taken as a homogenous group, the behaviors of these bow-headed "zombies" pose risks not only to their individual physical and mental health but also to their abilities to learn and communicate effectively. It is interesting to note that, in a way while bowing their heads to their mobile devices, these students are at the same time yielding to the fruits of their own learnings. The famous German philosopher Kant once said, "Living without goals is like sailing without a compass." The lack of goals in learning means that learning has lost its general direction, and it is not clear what it is for and how to discuss the benefits of "true" learning.

\section{Lack of thinking and innovation in learning}

Contemporary college students lack study arrangements of their own as well as personal plans for learning. More often than not, they simply review what they have learned prior to each examination, according to strictly to the scope of what will be covered on the test. This kind of "cramming education" is not uncommon on contemporary university campuses. Students have merely become recipients of knowledge, abiding strictly to the teachings of professors, unable to explore and apply their teachings any deeper than the way they have been taught how. To put it another way, in today's climate of learning, knowledge itself has become a widely recognized truth that has already been explored through and through by predecessors, and the responsibilities of students are simply to memorize and apply these truths. However, what we really need to do is to innovate based on a deeper and deeper understanding of the knowledge taught. Innovation and deep, abstract thinking are the true purposes of the cultivation of knowledge. It is clear by the lackluster innovative performance of college students that we have lost sight of this truth.

\section{Laziness and recalcitrance in study}

University is not only a place for college students to attain knowledge. It also serves as a valuable platform for the cultivation of their abilities and the quality of these abilities. Today the phenomenons of uncultured and uneducated people becoming fiscally rich and of the "wealthy second generation" have become very prevalent in society. On face value, these results of these highly visible phenomena have become strong evidence for a theory that reading is useless. This undoubtedly shakes the confidence of college students in their learnings, causing some college students to reevaluate their life values, even some to redefine the realization of 
life values and goals in terms of materialistic and fiscal wealth. But in the end, learning is and will always be the most important thing for college students. To lag behind others in learning means to lag behind others in market competitiveness. It is common knowledge that even in this era of new theories, new technologies, and new achievements, the truth that the people lagging behind their peers will be pushed out by their peers, of jobs, of relationships, of fulfilling lives, is the same for college students. The cultivation of truly talented individuals with extensive self-knowledge and self-learning abilities necessitates that they learn to overcome the state of mind that learning is full of anger and frustration. They must learn how to calm themselves down in order to learn healthy practices, master useful skills, and improve the overall qualities that will benefit them not only in the classroom and in the workforce, but throughout their lives.

\section{Opinions on Whether University Students Require Increased Academic Pressures}

The phenomenon is known in China as "happy middle school life, happy university life" has changed drastically in today's educational setting. I believe that many students in middle school have heard the teacher say: "Study hard now. You will be free to do what you want in a college." True to the words that have been taught by their middle school teachers, many college students attending university focus only on eating, sleeping, and playing video (or otherwise) games. Doing so, they waste their time. They believe that upon entering university, that they have "made it." They only seek to study enough to pass their examinations at the academic level and are consequently not interested in pursuing knowledge to a much deeper and more profound level. In this regard, we conducted a series of surveys at Wuyi University.

\section{Analysis of the views on academic pressure of Wuyi University students based on a sample group of university students}

Our survey is mainly on students' opinions regarding the policy of increasing the academic pressures of college students at Wuyi University. The questionnaire was filled out by 163 people, 156 them currently students at the university. Among them, first-year students, sophomores, and juniors accounted for the vast majority of the students surveyed, with half of whom were majoring in engineering, and the rest is mainly majoring in sciences and the liberal arts (findings reviewed below).

According to Figure 1 and Figure 2, 52.76\% of the students had little understanding of the policy to increase the academic workload of college students. All they really knew is that they have heard about it from the teachers and from fellow students. For all intents and purposes, they know very little about the actual purposes of and reasoning behind the policy. This demonstrates that either $52.76 \%$ of students were broadly unaware or willfully ignorant of the policies students are subject to at Wuyi University or that this specific policy and the way that it will be implemented are not very clear to students. Also of note, $28.83 \%$ of students have no understanding whatsoever of the relevant policies in regard to the governance of college students. Some students asked what the policy of increasing academic pressures for college students entails. These groups of the students surveyed, too, have little understanding of this policy. Contrarily, only $18.4 \%$ of students surveyed have a clear understanding of what it means to increase academics pressure on college students and have a very clear personal view on the matter.

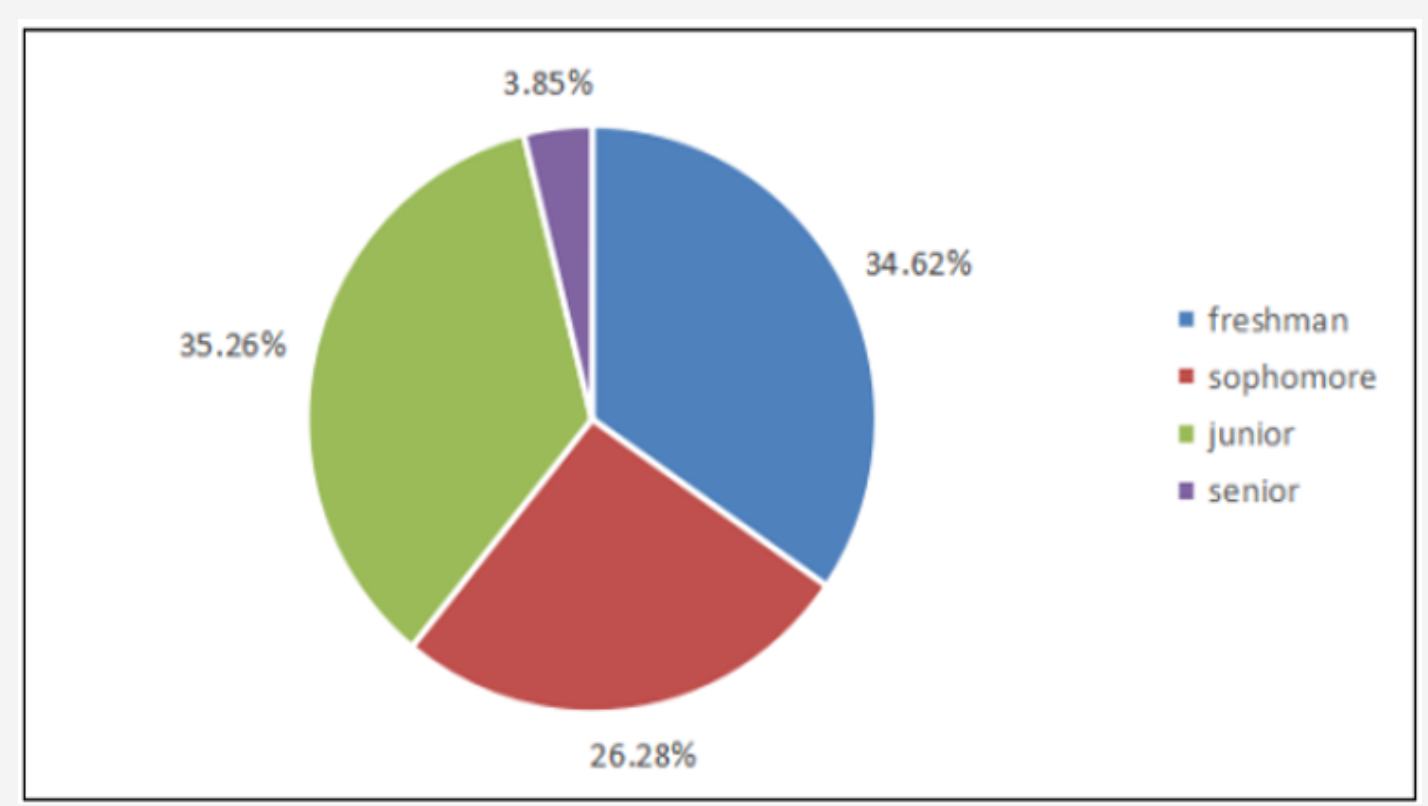

Figure 1: The proportion of students in different grade. 


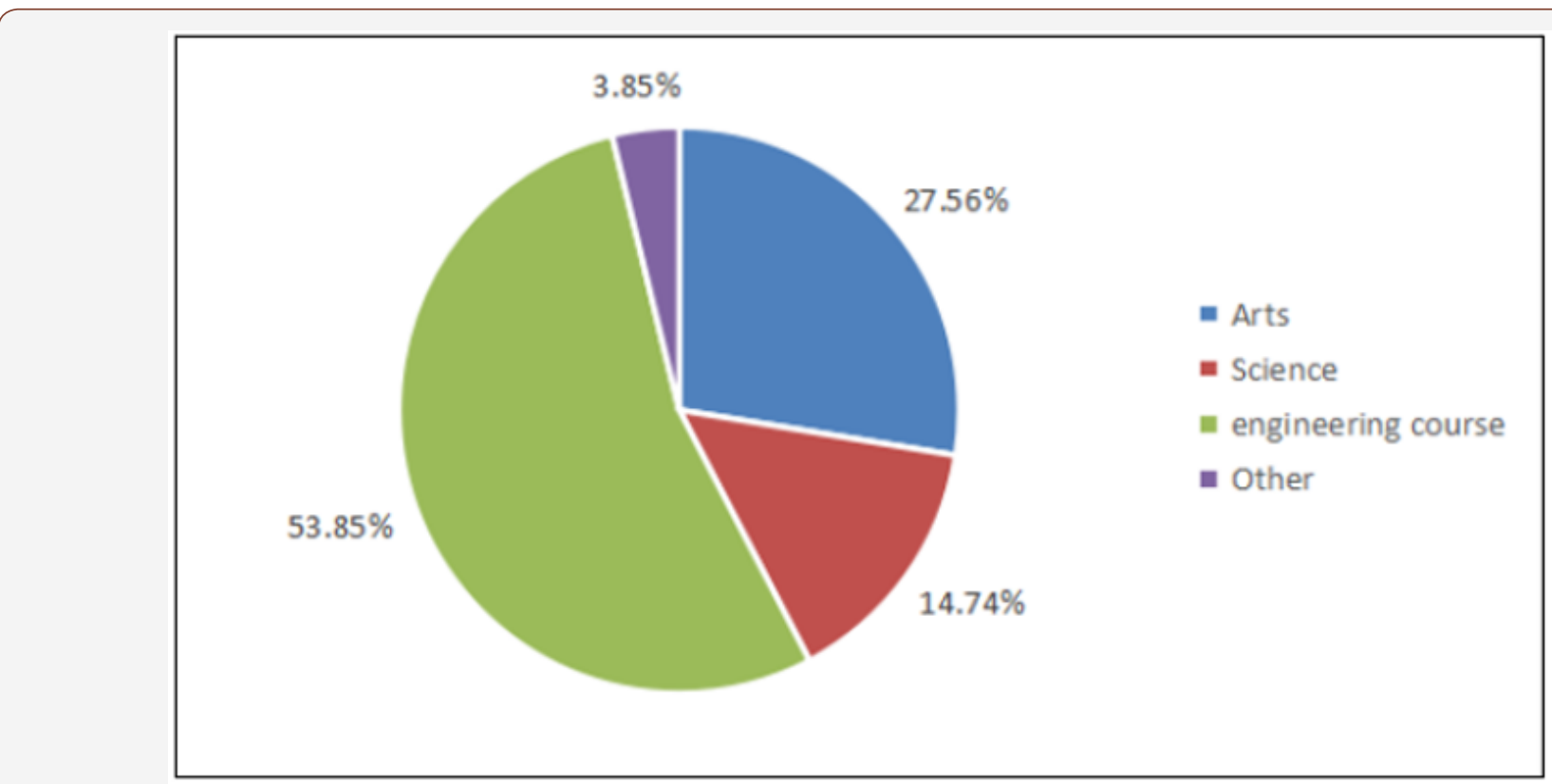

Figure 2: Types of university courses.

According to Figure 3,54.6\% of students surveyed thought that their current workloads were acceptable and refused to take unnecessary courses. On the other hand, $40.49 \%$ of students surveyed thought that their current coursework was already a heavy burden and that there should not be an increase in workload for college students. According to statistical interviews completed in person, the vast majority of engineering students thought that workload burdens were already heavy, while students majoring in the liberal arts and sciences thought the current workload was acceptable. Lastly, only $4.91 \%$ of students surveyed thought their current workloads were relatively light, and that the policy to increase student's academic pressures should be implemented.

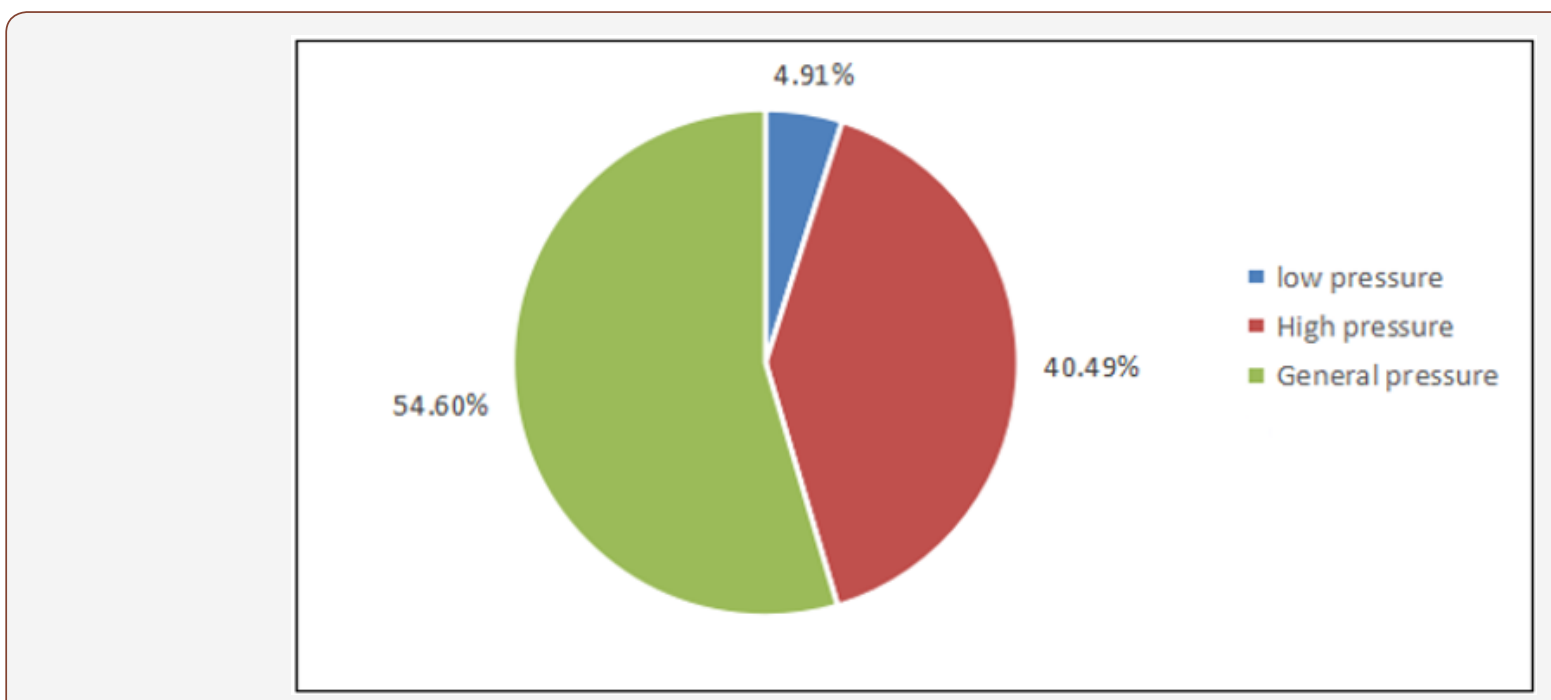

Figure 3: What's the current pressure.

According to Figure 4, the academic pressures of college comes the number of courses students take in any given semester. $60.49 \%$ of students thought that the bulk of the academic pressures came from the amount of assigned homework to them. The number of courses students take is comparatively more than they would have taken in middle and high school, and of course, the amount of homework assigned to college students will also be comparatively more than in primary and secondary schools. According to our Research, most of those surveyed actually thought that pressures mainly came from the dual pressures of graduation and employment; this group accounted for $76.54 \%$ and $74.69 \%$, respectively, of those surveyed. It is natural that students' graduation becomes more and more difficult over time, owing not strictly to graduation requirements, but rather to the actions and attitudes of students themselves. Many choose not to work hard. As a result, many students find it more and more difficult to graduate from university. The pressure of finding employment after graduation is also very significant. We found that $59.26 \%$ of students thought that the pressures exerted upon them came not from an academic source at all rather that they came mainly from psychological pressures. (Figure 5) Additionally, $34.57 \%$ of the students thought that pressures mainly came from extracurricular activities and college 
life. There will always be various organizations and activities for college students to attend to, more so now that they are "free to do what they want." However, attempting to undertake too many activities can make one feel under great pressure to fulfill extracurricular obligations. Finally, 8.08\% of students surveyed thought that the main source of pressures for college students came from the need to complete credits, economic hardships, instructors, research work, external physical stressors, and social and other stressors. According to the above data analysis, $30.13 \%$ of students hand in at least three-course assignments a week, depending on the difficulty of the course. According to students surveyed, there were many assignments that must be completed weekly. Of the students surveyed, $22.44 \%$ needed to hand in at least two-course assignments a week, which most of the students think is reasonable, while $33.34 \%$ of the students needed to hand in four or five-course assignments. There were a lot of students, many of whom say that the latter, having to complete four to five assignments a week, is very difficult. Those surveyed with this heavy workload state that their daily routines consist almost solely of going to class and working on homework after going to class. Only $7.69 \%$ of those surveyed are required only to turn in at least one-course assignment a week, which they find is relatively easy to do. These students find that they have a lot of free time. Additionally, $6.41 \%$ of students surveyed say they are required to hand in homework weekly for every class that they take. This is significant because some of these students are taking up to nine classes! Some surveyed students also said that they do not necessarily have any homework to turn in on a weekly basis, but that they find group work and lectures move at a fast pace for them. So how long exactly does it take the average student to finish all the homework assigned to them? According to Figure 6, 35.26\% thought they could finish in 3 hours. Less, 14.74\% stood the students that claimed they usually finished their work for the week within 2 hours, and $6.41 \%$ of students said they could finish all their assigned work for the week in 1 hour. However, in great contrast to the above-discussed students, $42.95 \%$ of students surveyed answered that it generally takes them more than 15 hours, some even 20 hours to finish their assigned work for the week. Because of the great variety of answers, the average time that students finished their weekly assignments is rather unclear. In short, some students replied that they have to work on homework all week long to get through their weekly assignments due to the difficulty as well as the quantity of the work assigned, while others said that their workload was relatively light and that they could finish their work with much time to spare. According to Figure 7, 83.33\% thought that they felt pressure when taking core courses. The correlation between core courses and respective majors is generally strong, and learning more in-depth. Compared with other courses, they will inevitably be more difficult. The homework assigned in these classes is also difficult and numerous. Instructors of these core courses also lecture at a very fast pace. As a result, the burden that these courses put on students is very heavy, indeed. In addition to the pressures exerted upon students by specialty courses, $35.8 \%$ of students surveyed thought that the bulk of the pressures came from foundational "pre-requisite" courses. This is due to the fact that the theoretical nature of pre-requisite courses is strong and, therefore, difficult for many students to understand. Additionally, 23.46\% thought that the pressures came from elective courses. Although elective courses are relatively simple and straightforward in nature, students are required to take a certain number of credits to graduate. Some of the elective courses that students take solely to make up credit hours are cumbersome and difficult to pass. Of those surveyed, another $22.22 \%$ of students thought that the pressures they experience come from general education courses. The forms that general education courses can take are very diverse. Some are taught using video or slideshows, other research work, or research papers, which can take a lot of time. Should a policy of increasing academics pressures for college students be implemented? To put this in perspective, $46.91 \%$ of students surveyed supported a policy to increase academic pressure on college students. They thought that the university life of many college students was too self-indulgent and relaxed. They thought that the quality of the pressures that college students face should be improved as well. Students were quick to point out that some core courses were too abstract, and that college students were made to push through these inane courses, which led to student recalcitrance in learning. Students, they said, should be pressured in specific and productive ways. It is just this targeted, "productive pressure" that will push students to become better versions of themselves. Unsurprisingly, some students, coddled and protected from personal challenge and growth from youth, also believed that pressure was a phenomenon specific to the school, and that when they complete their studies and finally enter society, the majority of social, psychological, and work pressures would mysteriously evaporate and disappear from their lives. Increasing pressures in the short-term, therefore, could dramatically improve college students' (who have not faced like pressures before) ability to combat frustration, so by the time they complete their college postsecondary studies, they will have an idea of how to struggle, how to persevere, and how to carry on despite numerous external pressures. However, on the other hand, $67.9 \%$ of the students did not support a policy to increase the workload for college students. This group consisted mainly of engineering and science students who thought that pressures exerted on university students were already excessive and even mentioned that they hoped the university would reduce their respective workloads. (Figure 8) Other students thought that though the workload policy of students is generally good, there are still many problems. For example, selfdisciplined college students may experience greater pressures and workload. And for lazy students, there may be similar if not more homework and more academic pressures (owing to the fact that they may not complete their assignments on time), but these students may not care about their studies as much as diligent students, and so may not experience the same consequences in the same way as such students. We should give college students more control over their own time to learn to study and live independently, instead of being pushed forward linearly, policy after policy. 


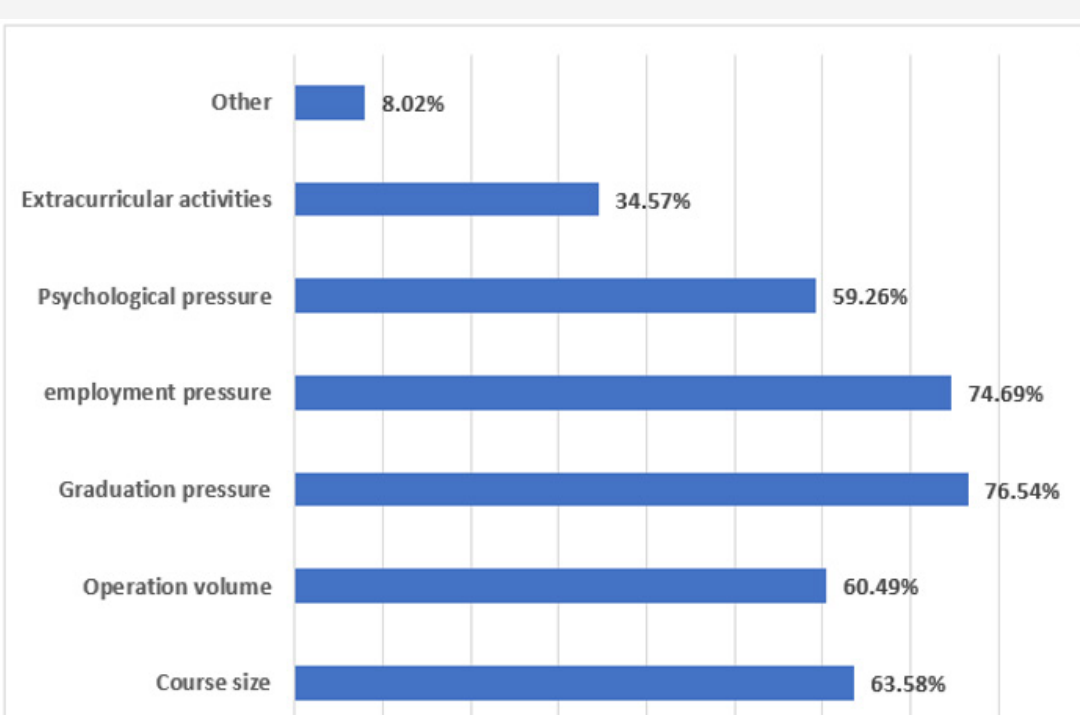

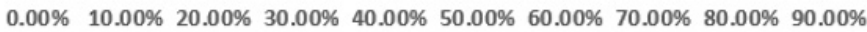

nercentage of students (Same below)

Figure 4: Pressure sources of College Students (multiple selection).

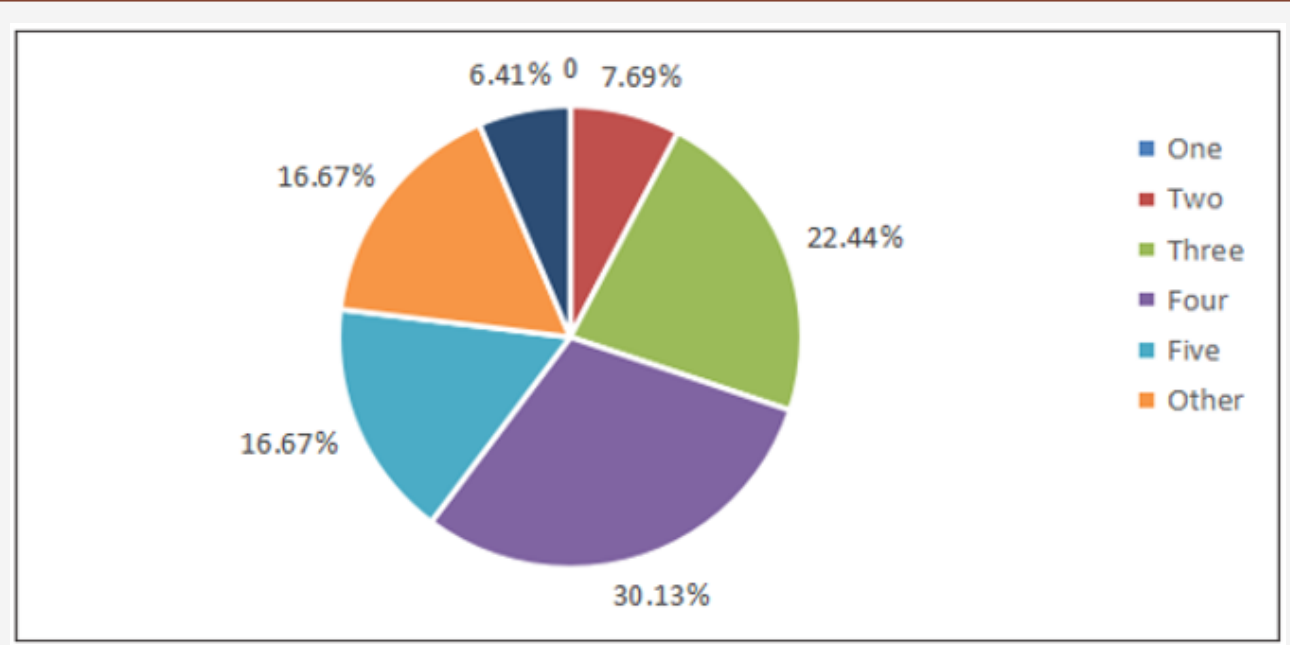

Figure 5: How many assignments should be handed in every week on average.

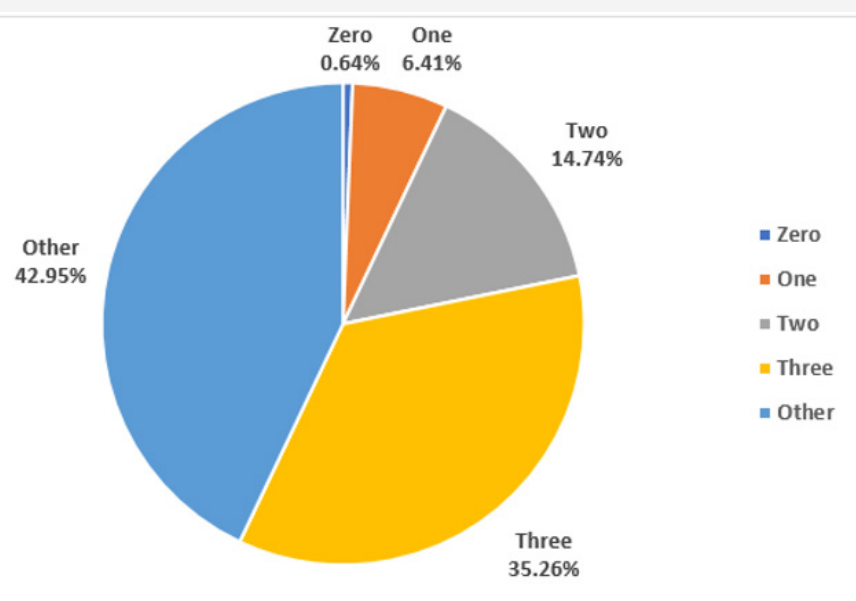

Figure 6: Time required to complete the work every week. 


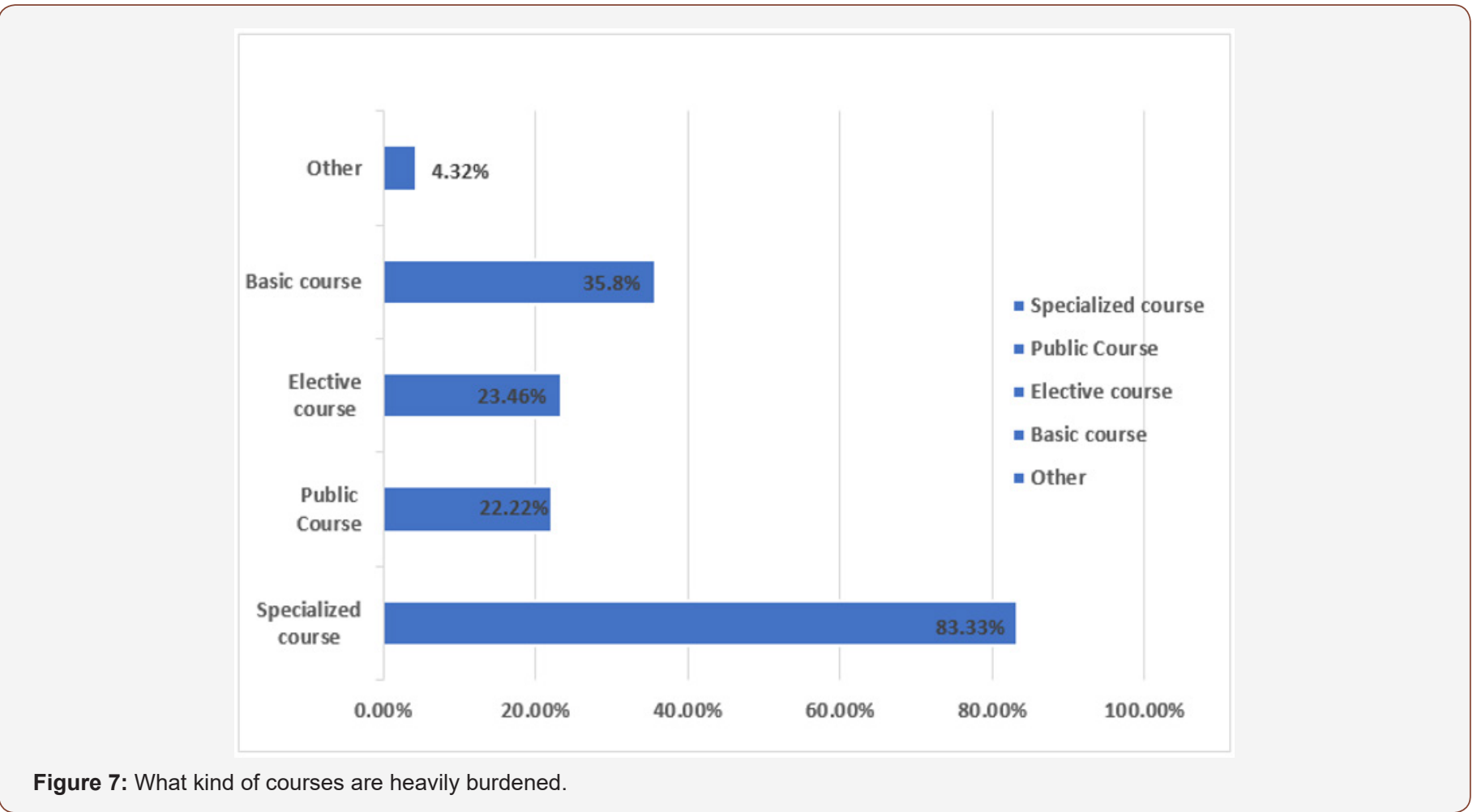

Figure 7: What kind of courses are heavily burdened.

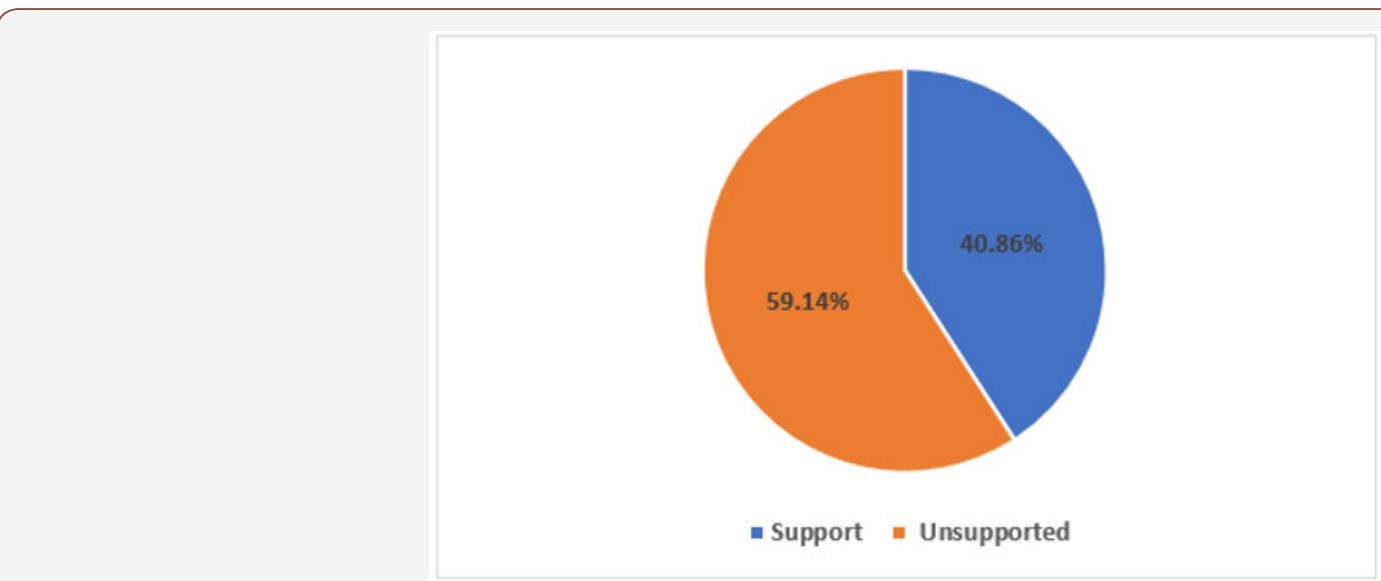

Figure 8: Whether to support the policy of increasing pressure for College Students.

In which aspects, therefore, would it be beneficial for students to see an increase in workload? According to Figure 9, 70.37\% thought that core courses and professionally applicable skills should generally be more supported because life after graduation, employment especially, mostly make use of these core pieces of knowledge and skills. If a good foundation is not established in schooling, this will certainly pose a big problem to students following their graduations and entrance into the workforce. Similarly, $37.65 \%$ thought that more of an emphasis should be placed on pre-requisite courses in order to (similar to the function of core courses) lay a good foundation. This is the result in an easier time for students to learn more difficult concepts. In another significant group, 59.26\% of surveyed students thought more emphasis should be placed on "practical" application-related activities such as solving real-world problems through assigned homework. After all, only when students have experience in application and have practiced it themselves, can they attain a proper understanding of the material. Finally, another $17.9 \%$ of students thought that the best way to productively increase academic pressure on college students at Wuyi University was to simply increase the amount of homework assigned per week. According to Figure 10, 77.3\% trusted teachers to increase academic pressures appropriately, by reducing the number of unnecessary courses while increasing the number of useful and interesting courses and by increasing the difficulty of courses that were previously too easy. On the other hand, $6.75 \%$ of the students thought that teachers would reduce appropriately reduce academic pressures. Also, $14.11 \%$ of the students thought that a policy increasing students' academic pressures would have no impact on teachers. According to Figure $11,72.22 \%$ of students claimed that they were interested in promoting and strengthening ideological, conceptual, and educational innovation and entrepreneurship education. By improving upon a model or concept, a student's interest in learning can be stimulated, and efficiency can be increased as well. of 
surveyed, $67.28 \%$ were interested in cultivating their motivation in learning and professional interests. Of surveyed, $65.43 \%$ were interested in improving the quality of teaching and updating course content. Also, of surveyed, $34.57 \%$ were interested in improving the quality of academic challenges of college students. Another $31.48 \%$ of surveyed students were interested in improving the quality of the design of the graduation theses. Finally, $27.16 \%$ of students were interested in strengthening the process of evaluating learning (i.e., the grading system), and phasing in a system of assessment that would be more conducive to students' studies. According to Figure 12, 56.41\% of the students thought that at least some of the courses they were taking were useful and that the knowledge acquired in core courses may be more useful than that acquired in other classes. They said that some elective courses had little to no effect on their learning experience. Of those surveyed, $33.97 \%$ of students also thought that most courses had a great effect on future development. Additionally, 7.69\% of the students thought that most courses had no external applications, that most of what was taught was useful only for the exams in the class. Finally, $1.92 \%$ of the students surveyed thought that most classes had no applications whatsoever or had no opinion either way.

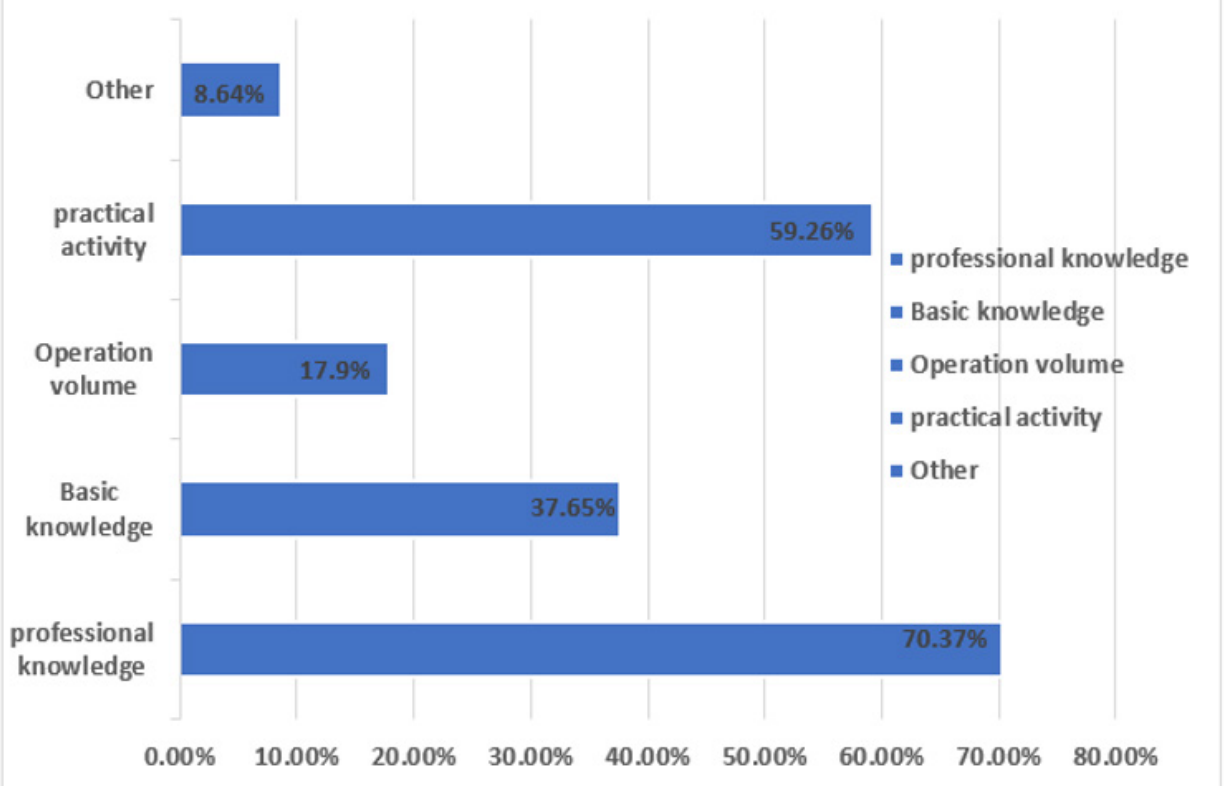

Figure 9: What should college students' burden increase be reflected in (multiple choice).

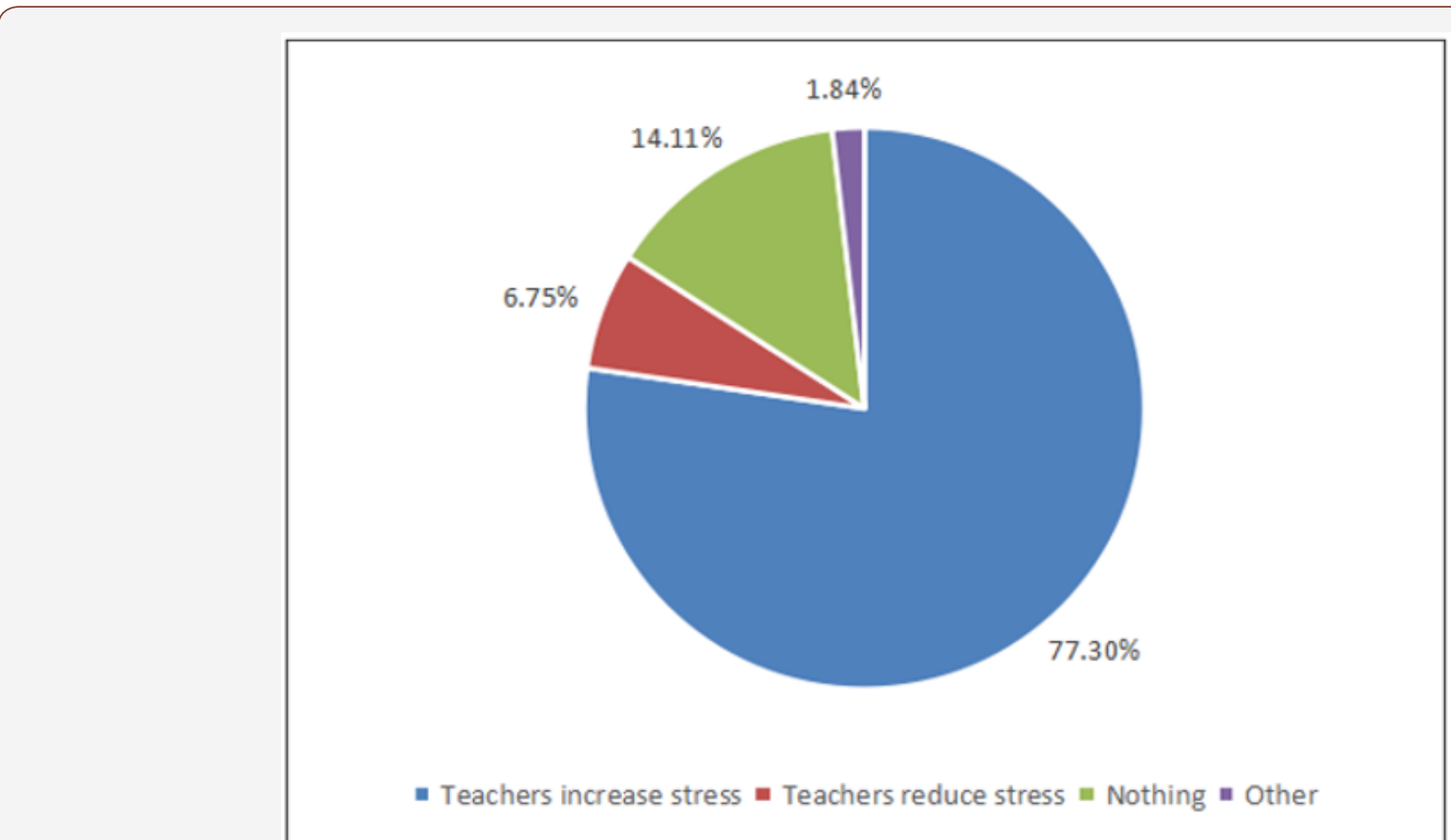

Figure 10: The impact of this policy on Teachers. 


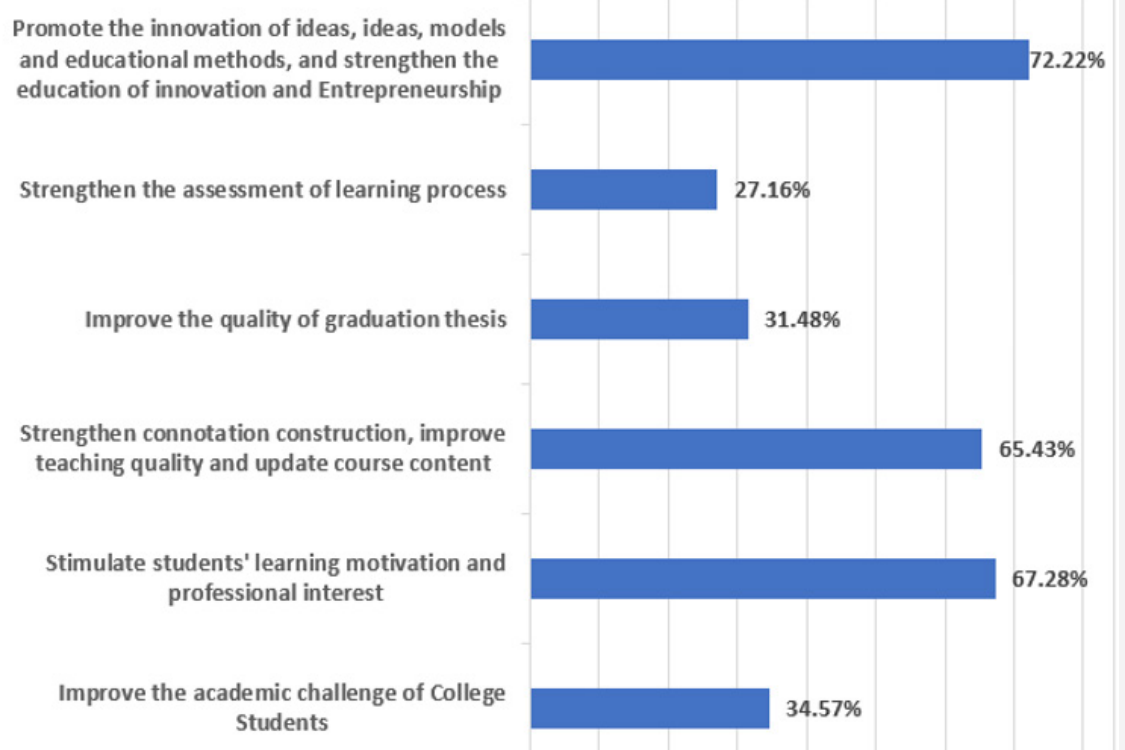

Figure 11: Those who are more interested in the policy of increasing students' burden (multiple selection).

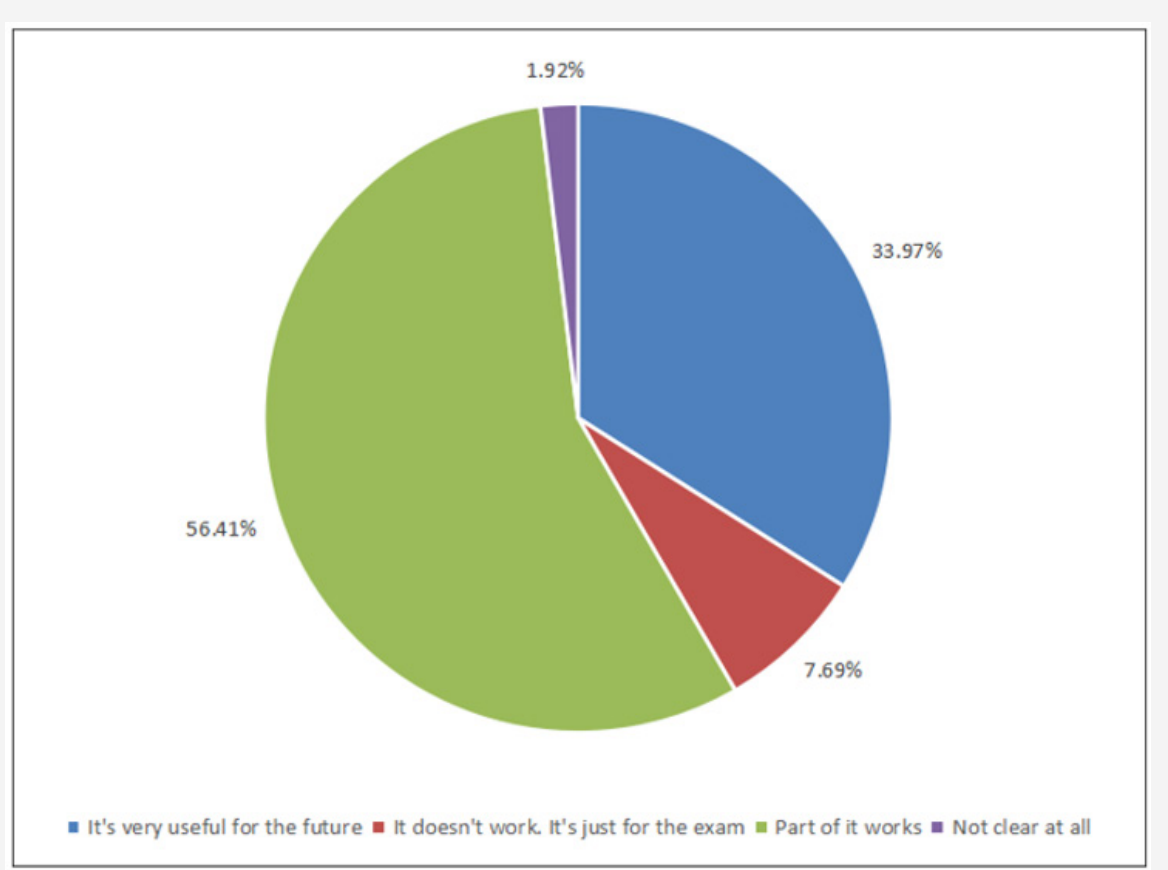

Figure 12: Value to own curriculum.

Views and Suggestions Regarding the Increase of the Workloads of Contemporary College Students

\section{The specific implementation of an increase in students' academic pressures}

To properly increase workload on college students, we should not only discuss its benefits intellectually but must also take concrete actions. This is particularly important in the creation of exceptional courses and the elimination of unnecessary courses. Graduation requirements should be added to, and the difficulty of graduation increased, to improve the quality of students' graduation-required theses. Our students should learn real-worldapplicable skills and useful technologies that will help them after graduation. The difficulties of life, as we know, does not end for students once they graduate.

Additionally, students should see a reasonable increase in academic workload. The increase in students' academic workload must not be a blind venture. It is, therefore, of paramount importance to carefully analyze the effects of such workload increases on students majoring in different subjects. We must not simply make idle people busy, and already busy people busier. The difference in workload and graduation requirements of different 
majors must also be considered (as each major has often drastically different characteristics and requirements than another) to increase academic pressures for students of some majors and reduce academic pressures for others. Thus, students of different majors and specialties can reasonably develop in a more beneficial and healthy way, and in a way that will not affect the quality of the education each student receives.

\section{Return teaching to its roots}

It is necessary to increase students' academic pressures carefully and reasonably, to enhance the quality of their academic challenges (and not simply their quantity), to encourage students to self-motivate to learn, to stimulate their professional interests, to increase the difficulty of graduation, and to reflect individual students' improvements on their grade reports.

The second is to return teaching to its roots. Teachers should be guided to have a deep love for teaching, to devote themselves to teaching to the benefit of students, to research teaching such as techniques to most effectively teach pupils, and to devote themselves to teaching and educating students. Teachers should be held, first and foremost, to moral standards as the most important criterion in the evaluation of the quality of teachers. A "one-vote veto system" should also be implemented to be used in the evaluations of teachers up for promotion. We should also adhere to proper and appropriate political direction by promoting a combination of core knowledge education and ideological and political education through the amalgamation of knowledge-based systems of education, value-based systems of education, and innovation-based systems of education. Lastly, we should promote innovation in school organizations and administration. By doing all these things, we strive, through education, to realize the Chinese dream of serving and strengthening the country.

\section{How to Improve the Learning Situation Contemporary College Students}

\section{Improvement at the societal level}

Society needs to provide more opportunities to meet the employment needs of college students. In contemporary society, it is an indisputable fact that it is difficult for college students to obtain employment. To a large extent, it has become the main reason some college students' have such negative attitudes toward learning. It is necessary to reverse this trend. Society must play a positive role in guiding students. There should be timely releases of the latest employment information. We should do a better job at surveying the current employment landscape to better identify employment trends, so as to facilitate college students' understanding of the latest trends and needs of society. This will allow students to adjust their developmental directions and goals. The employment situation of college students directly affects the development of higher education through peoples' perception of its value. Therefore, society also has a responsibility and an obligation to strive to develop the economy and actively adjust the industrial structure, so as to mutually benefit both the cultivation of competent workers (taking place in colleges and universities across the country) and the use of these competent workers by society [15].

\section{Improvement at the teacher level}

Teachers must give more guidance to help college students learn and innovate. A responsible educator should actively try to guide college students to establish a proper outlook on life and on their values. On the premise that studying at a university is different from doing so in a middle school, teachers should give students corresponding guidance and timely help. They should provide them with feasible suggestions and effective psychological guidance so that they are prepared for the real world. In the process of educating college students, instructors should not only focus on imparting textbook knowledge, but also pay more attention to the cultivation of students' thinking and innovation abilities. The mission of universities is to cultivate the ability of students to explore their learnings, to seek the truth, and to stimulate ideas and innovation. However, the educational model of some universities is now in marked violation of this mission. Therefore, it is necessary for teachers to recognize their responsibilities and constantly stimulate students' enthusiasm to explore the truth.

\section{Improvement at the student level}

Student cadres should take the lead in guiding college students as well, due to the important roles they play in the work of college students. However, we must be aware of the fact that even if the work of student cadres is excellent, it is difficult to establish a good image of them among their peers. The learning situation and attitude of student cadres have a subtle impact on the learning of other students in the class. Their serious attitude toward learning will also cultivate a conducive atmosphere for learning in the classroom. With such enthusiasm for learning that student cadres have, the learning of the whole class will be improved, and in turn, class management should be noticeably smoother. During their spare time, student cadres should make full use of their own privileged position to organize some experiences or activities for the class. Such class activities will allow students to gather together and deepen their learning experience, learning methods, academic Research, etc., through conversation and discussion. With such a platform for mutual exchange, we can more easily understand new ideas and new techniques, so as to improve students' own learning efficiency.

\section{Improvement by the students themselves}

Students themselves do not want to be enterprising. Even if they have the best external conditions, it is difficult to change the current problems in their study. So that college students can improve upon their own ideas, correcting their attitudes, especially negative ones, toward learning is particularly important. In fact, it is not necessary to "work hard" to learn. It is more important to be able to accumulate experience through long-term learning and to find the most suitable method for each individual student's learning. Only through a life of continued learning can they stand out from the crowd and take the lead in the competition for jobs. Learning is not simply the acquisition of knowledge, but also the ability to find, analyze, and solve problems from different perspectives and points of view. In the long run, true innovative thinking can be cultivated. In the analysis and thinking of this paper, we can see that the autonomous learning abilities of contemporary college students are still lacking, and their abilities to explore and uncover deeper 
knowledge still leaves much to be desired. As mentioned above, the college students of the post-90s generation become an important force in social development. A group of college students with hopes and dreams is about to enter society. We have reason to believe that their emergence will inject fresh vitality into the whole of society and that they will also contribute to the realization of the dream of China.

\section{Acknowledgment}

Authors would like to thank Prof. Jiujiang Zhu for his guidance in writing this paper, and also for his financial support through the project "High Education funding of Guangdong Province: 2018KZDXM072".

\section{Conflict of Interest}

None.

\section{References}

1. Zhao Jiao, Lou Linyan (2015) Analysis of the current situation and Countermeasures of contemporary college students' learning [J]. Education and teaching forum 46: 205-206.

2. Zhou Xiaorong (2016) Practice and experience of the flipped classroom in Applied Electrochemistry Teaching. Guangdong chemical industry (20).

3. Wang Chunqing. (2010) Analysis of the current situation of College Students' learning and Research on countermeasures. Journal of Jilin Agricultural Science and technology college (03).

4. Shao Mingqun, Wu Jiagui (1999) Students' learning status and adjustment strategies. Journal of Pengcheng Vocational University (01).

5. Ge Cuicui (2016) Learning status and improvement suggestions of contemporary college students [J]. Education modernization (40). 